\title{
Pengaruh Suhu dan Jumlah Penyeduhan terhadap Kadar Kafein Terlarut dalam Produk Teh Hijau Kering dengan Metode KCKT
}

Febri Annuryanti ${ }^{1 *}$, Masruratos Zahroh ${ }^{2}$, Djoko Agus Purwanto ${ }^{1}$

${ }^{1}$ Departemen Kimia Farmasi, Fakultas Farmasi, Universitas Airlangga, Surabaya

${ }^{2}$ Fakultas Farmasi, Universitas Airlangga, Surabaya

*Corresponding author: febriannuryanti@yahoo.com

\begin{abstract}
Background: Tea is one of the most consumed drinks in the world; which has benefits for human health. In addition to being beneficial for health, tea also containing caffeine which has an adverse effect on the body if excessively consumed. Excessive caffeine consumption can cause insomnia, anxiety, delirium, tachycardia, extrasistole, increased breathing, muscle tremors and diuresis. For these reasons, currently decaffeinated tea is preferred. Objective: This research aimed to determine the effect of temperature and brewing frequency on dissolved-caffeine concentration in dried green tea product samples. Methods: In this study, three different temperatures $\left(50^{\circ} \mathrm{C}, 70^{\circ} \mathrm{C}, 100^{\circ} \mathrm{C}\right)$ were used. Dissolved-caffeine concentration was analized by HPLC method using C-18- $\mu$ bondapak column; methanol: water: acetic acid $2 \% \mathrm{v} / \mathrm{v}$ (30:65:5) as mobile phase with flow rate of $0.45 \mathrm{~mL} / \mathrm{min}$ and detection was done at wavelength of $272 \mathrm{~nm}$. The HPLC method was validated for selectivity, linearity, accuracy, precision, $L O D$ and $L O Q$ parameters. The results showed that all validation parameters met the requirements. Results: The result of the study revealed that the increasing of brewing temperature was related to the rose of dissolved-caffeine concentration in green tea samples, and the increasing of brewing frequency was related to decreasing of dissolved-caffeine content in green tea samples. The highest levels of caffeine was found in the first brewing at temperature of $100^{\circ} \mathrm{C}$, while the lowest caffeine content was in the third brewing at temperature of $100^{\circ} \mathrm{C}$. Conslusion: In conclusion, the levels of caffeine in the green tea was affected by temperature and frequency of brewing.
\end{abstract}

Keywords: green tea, caffeine, HPLC, brewing

\begin{abstract}
Abstrak
Pendahuluan: Teh adalah salah satu minuman yang paling banyak dikonsumsi di dunia dan memiliki khasiat bagi kesehatan. Selain memiliki manfaat, teh juga mengandung kafein yang dapat memberikan efek samping apabila dikonsumsi secara berlebihan. Efek samping yang ditimbulkan diantaranya insomnia, ansietas, takikardia dan napas yang cepat. Oleh karena itu, saat ini diinginkan teh dengan kandungan kafein yang rendah. Tujuan: Penelitian ini bertujuan untuk menentukan efek suhu dan jumlah penyeduhan terhadap konsentrasi kafein yang terlarut dari sampel kering teh hijau. Metode: Pada studi ini digunakan tiga macam suhu $\left(50^{\circ} \mathrm{C}, 70^{\circ} \mathrm{C}, 100^{\circ} \mathrm{C}\right)$ dan tiga kali pengulangan penyeduhan. Kafein terlarut dianalisa dengan menggunakan kondisi KCKT sebagai berikut: kolom C-18- $\mu$ bondapak, fase gerak metanol : air : asam asetat $2 \% \mathrm{v} / \mathrm{v}$ (30:65:5) dengan laju alir 0,45 $\mathrm{mL} / \mathrm{menit}$. Deteksi dilakukan pada panjang gelombang $272 \mathrm{~nm}$. Parameter validasi yang dilakukan meliputi selektifitas, linieritas, akurasi, presisi, LOD dan LOQ. Seluruh parameter validasi memenuhi persyaratan yang telah ditetapkan. Hasil: Kadar kafein tertinggi diperoleh pada penyeduhan pertama pada suhu $100^{\circ} \mathrm{C}$ dan kadar kafein terendah ditemukan pada penyeduhan ketiga pada suhu yang sama. Kesimpulan: Berdasarkan hasil analisis, dapat disimpulkan bahwa suhu dan jumlah penyeduhan dapat mempengaruhi kadar kafein terlarut pada teh hijau.
\end{abstract}

Kata kunci: teh hijau, kafein, HPLC, penyeduhan 


\section{PENDAHULUAN}

Teh adalah minuman yang terbuat dari tanaman Camellia sinensis dan merupakan salah satu minuman yang paling banyak dikonsumsi di dunia. Teh mengandung katekin yang dipercaya dapat memberikan manfaat bagi kesehatan dan kecantikan (Syah, 2006). Selain bermanfaat bagi kesehatan, di dalam teh juga terdapat kafein yang dapat berakibat kurang baik bagi tubuh apabila dikonsumsi secara berlebihan (Fernandez-Caceres dkk., 2001). Kandungan kafein dalam teh hijau sebesar 3,4\% b/b, dalam teh hitam, teh oolong dan teh putih masingmasing sebesar $3,5 \% \mathrm{~b} / \mathrm{b} ; 3,7 \% \mathrm{~b} / \mathrm{b}$ dan $4,85 \% \mathrm{~b} / \mathrm{b}$ (Syah, 2006).

Kafein memiliki efek farmakologis yang bermanfaat secara klinis, seperti menstimulasi susunan saraf pusat sehingga dapat mengurangi rasa kantuk dan menambah semangat, relaksasi otot polos terutama otot polos bronkus dan stimulasi otot jantung (Fulder, 2004). Akan tetapi, pada tubuh yang mempunyai masalah dengan keberadaan hormon metabolisme asam urat, maka kandungan kafein dalam tubuh akan memicu terbentuknya asam urat tinggi (Burnham, 2001). Efek kafein yang lain dapat meningkatkan denyut jantung dan berisiko terhadap penumpukan kolesterol, menyebabkan kecacatan pada anak yang dilahirkan (Hoeger dkk., 2002).

Meskipun kafein aman dikonsumsi, zat tersebut dapat menimbulkan reaksi yang tidak dikehendaki jika dikonsumsi secara berlebihan seperti insomnia, gelisah, delirium, takikardia, ekstrasistole, pernapasan meningkat, tremor otot dan diuresis. Oleh karena itu, saat ini lebih disukai teh tanpa kafein (Misra dkk., 2008).

Khasiat dan dampak berbahaya teh tergantung pada cara menyeduh teh. Semakin lama teh direndam, maka kafein dalam teh akan semakin terekstraksi dan terjadi oksidasi (Putri \& Ulfin, 2015). Berdasarkan kebiasaan masyarakat di Indonesia yang menyeduh teh dengan air hangat atau dengan air panas baik yang berasal dari pemanas dispenser dengan suhu $70^{\circ} \mathrm{C}$ sampai suhu $80^{\circ} \mathrm{C}$ ataupun air yang mendidih dengan suhu $100^{\circ} \mathrm{C}$, maka digunakan variabel suhu ekstraksi dengan pelarut air pada suhu 50,70 , dan $100^{\circ} \mathrm{C}$. Pada beberapa masyarakat juga ditemukan teh yang digunakan berulang-ulang dalam sehari. Oleh sebab itu, peneliti ingin mengetahui kadar kafein terlarut dalam produk teh hijau yang diseduh secara berulang.

Untuk analisis kandungan kafein di dalam produk teh hijau digunakan metode Kromatografi Cair Kinerja Tinggi (KCKT) dengan detektor PDA (Photo Diode
Array). Sampel dideteksi pada panjang gelombang $272 \mathrm{~nm}$ dan dipisahkan dengan menggunakan kolom C-18 $\mu$ bondapak dengan fase gerak air: metanol: asam asetat $2 \%=65: 30: 5(\mathrm{v} / \mathrm{v} / \mathrm{v})$. Sebelum dilakukan penetapan kadar kafein menggunakan metode KCKT, dilakukan validasi metode analisis yang akan digunakan. Validasi menjadi faktor penting untuk membuktikan bahwa hasil analisis dapat dipertanggung jawabkan. Beberapa parameter validasi yang diuji dalam penelitian ini meliputi linieritas, selektivitas, akurasi, presisi, LOD dan LOQ.

\section{BAHAN DAN METODE}

\section{Bahan}

Produk teh hijau Kepala Djenggot ${ }^{\circledR}$ (PT. Gunung Subur Sejahtera, Solo-Indonesia), standar kafein (Merck, Germany), metanol pro KCKT (Merck, Germany), asam asetat glasial p.a (Merck, Germany), aquabidestillata (Ikapharmindo Putramas, Indonesia).

Alat

Shimadzu LC-20AD yang dilengkapi dengan detektor PDA SPD-M20A, degasser DGU-20A5R. Kolom $\mu$-Bondapak C18 Waters $(3,9$ x $300 \mathrm{~mm}$, $10 \mu \mathrm{m})$, Spektrofotometer UV-Vis Shimadzu HP 8452 single beam. Analisis dilakukan pada panjang gelombang $273 \mathrm{~nm}$, suhu $30^{\circ} \mathrm{C}$ dan volume injeksi sebesar $100 \mu \mathrm{L}$.

\section{Metode}

\section{Penetapan kadar air}

Penetapan kadar air dalam sampel dilakukan pada sampel teh hijau dengan metode gravimetri sesuai SNI 3945:2016 (Badan Standarisasi Nasional, 2016).

\section{Optimasi kondisi KCKT}

\section{Panjang gelombang maksimum}

Penentuan panjang gelombang maksimum dilakukan dengan melakukan scanning terhadap larutan standar kafein menggunakan spektrofotometer UV-Vis pada rentang $210-300 \mathrm{~nm}$ dengan blanko metanol.

\section{Komposisi dan kecepatan alir fase gerak}

Optimasi fase gerak dilakukan dengan mengubah komposisi air - metanol - asam asetat $2 \%$. Untuk kecepatan alir, dilakukan variasi kecepatan alir fase gerak dimulai dari $0,45 \mathrm{~mL} /$ menit; $0,8 \mathrm{~mL} /$ menit, dan $1 \mathrm{~mL} /$ menit.

\section{Validasi metode}

\section{Selektivitas}

Selektivitas diuji menggunakan 3 macam larutan, yaitu larutan standar kafein $80 \mathrm{ppm}$, larutan sampel teh hijau, dan larutan sampel teh hijau yang sudah ditambahkan larutan standar kafein 80 ppm. Larutan yang telah dibuat disaring dengan menggunakan 
membran filter Whatman 0,22 $\mu \mathrm{m}$ dan kemudian diinjeksikan pada KCKT dengan metode terpilih. Pada resolusi (Rs) yang menyatakan keterpisahan dua senyawa atau puncak yang berdekatan dalam kromatogram. Dikatakan selektif jika nilai Rs $\geq 1,5$ (Yuwono \& Indrayanto, 2005).

\section{Linieritas}

Data linieritas diperoleh dengan membuat lima macam larutan standar kafein dengan rentang konsentrasi antara 80 - 120\% dari konsentrasi sampel. Larutan standar kafein kemudian disaring dan disuntikkkan pada KCKT. Linieritas diperoleh dengan menghitung persamaan garis regresi $\mathrm{y}=\mathrm{ax}+\mathrm{b}$ dan harga r (koefisien korelasi).

Akurasi

Uji akurasi dilakukan dengan cara adisi standar. Sampel yang telah dipreparasi ditambah dengan larutan standar kafein hingga mencapai konsentrasi 80\%, $100 \%$ dan $120 \%$. Sampel uji akurasi kemudian disaring dan diinjeksikan ke dalam sistem KCKT terpilih. Data yang diperoleh diolah untuk memperoleh nilai \% perolehan kembali.

\section{Presisi}

Larutan standar kafein diinjeksikan pada KCKT terpilih sebanyak 6 kali pengulangan kemudian dihitung nilai Koefisien Variasi (KV).

\section{Limit deteksi (LOD) dan kuantitasi (LOQ)}

Limit deteksi dan kuantifikasi diperoleh dengan menggunakan 5 konsentrasi terkecil larutan standar kafein yang masih memberikan respon ketika diinjeksikan pada kondisi KCKT terpilih. Nilai LOD dan LOQ dihitung berdasarkan data simpangan baku dan slope.

\section{Penetapan kadar kafein dalam sampel}

Sampel ditimbang sebanyak 4,0 g dan diseduh dengan $80,0 \mathrm{~mL}$ air suling (suhu 50,70 , dan $100^{\circ} \mathrm{C}$ ) sambil diaduk sesekali, kemudian didiamkan selama 30 menit. Sampel kemudian disaring dan dimasukkan ke dalam labu ukur 100,0 mL dan ditambahkan air suling hingga tepat tanda dan dikocok hingga homogen. Larutan sampel diambil sebanyak 5,0 mL kemudian dimasukkan ke dalam labu ukur 10,0 mL dan ditambahkan metanol sampai tepat tanda dan di homogenkan. Sampel selanjutnya disaring dan diinjeksikan pada kondisi KCKT terpilih. Tahap ini dilakukan triplo. Penyeduhan dilanjutkan pada residu profil kromatogram di dapatkan data waktu retensi (tR) yang digunakan untuk menghitung selektivitas $(\alpha)$ dan pertama dan kedua. Dari kromatogram yang didapat, diamati area yang diperoleh, kemudian dimasukkan dalam persamaaan regresi kafein, sehingga diperoleh kadar kafein dalam sampel produk teh hijau Kepala Djenggot PT. Gunung Subur Sejahtera, Solo Indonesia.

\section{HASIL DAN PEMBAHASAN}

\section{Penetapan kadar air}

Berdasarkan SNI (Badan Standarisasi Nasional, 2016), persyaratan kadar air dalam produk teh hijau adalah $\leq 8 \%$. Berdasarkan uji penetapan kadar air, diperoleh kadar air pada sampel teh hijau sebesar $7,35 \%$ (Tabel 1), sehingga dapat dinyatakan bahwa kadar air dalam sampel teh hijau telah memenuhi persyaratan.

Tabel 1. Hasil penetapan kadar air pada sampel teh hijau

\begin{tabular}{|c|c|c|c|}
\hline \multirow[t]{2}{*}{ Keterangan } & \multicolumn{3}{|c|}{ Replikasi ke - (gram) } \\
\hline & 1 & 2 & 3 \\
\hline Berat Sampel & 5,0023 & 5,0067 & 5,0114 \\
\hline \multicolumn{4}{|l|}{ Berat Cawan: } \\
\hline 1 jam $\left(w_{0}\right)$ & 20,3325 & 20,6595 & 20,6754 \\
\hline \multicolumn{4}{|c|}{ Berat Cawan + sampel (gram) } \\
\hline $\begin{array}{l}\text { Sebelum } \\
\text { Pemanasan }\left(\mathrm{w}_{1}\right)\end{array}$ & 25,3335 & 25,661 & 25,6830 \\
\hline 3 jam pertama & 24,9916 & 25,3144 & 25,3587 \\
\hline $\begin{array}{l}1 \text { jam } \\
\text { berikutnya }\end{array}$ & 24,9657 & 25,2928 & 25,3148 \\
\hline $\begin{array}{l}1 \text { jam } \\
\text { berikutnya }\left(\mathrm{w}_{2}\right)\end{array}$ & 24,9652 & 25,2928 & 25,3148 \\
\hline $\begin{array}{ll}\text { Berat } & \text { Sampel } \\
\text { Kering } & \\
\end{array}$ & 4,6339 & 4,6381 & 4,6429 \\
\hline$\%$ Kadar air & $7,36 \%$ & $7,36 \%$ & $7,35 \%$ \\
\hline $\begin{array}{l}\text { Rerata } \\
\% \text { kadar air }\end{array}$ & \multicolumn{3}{|c|}{$7,35 \% \pm 0,01$} \\
\hline
\end{tabular}

\section{Optimasi kondisi KCKT}

\section{Panjang gelombang maksimum}

Pengukuran panjang gelombang maksimum dilakukan menggunakan larutan standar kafein konsentrasi 40 dan 50 ppm. Berdasarkan pengamatan absorban larutan standar kafein (Gambar 1), dipilih panjang gelombang $272 \mathrm{~nm}$ untuk analisis kadar kafein dalam produk teh hijau. 




Gambar 1. Penentuan panjang gelombang maksimum menggunakan spektrofotmeter UV-Vis. Panjang gelombang $272 \mathrm{~nm}$ dipilih untuk analisis kafein terlarut dalam teh hijau.

\section{Komposisi dan Kecepatan Alir Fase Gerak}

Hasil optimasi komposisi dan kecepatan fase gerak, menunjukkan bahwa metanol : air : asam asetat $2 \%$ dengan komposisi 30:65:5 dan laju alir 0,45 mL/menit mampu memberikan selektifitas yang baik dengan harga $\mathrm{Rs} \geq 1,5$.

\section{Validasi metode}

\section{Selektifitas}

Hasil uji selektifitas menunjukkan bahwa kafein dalam sampel teh hijau dapat terpisah sempurna dengan senyawa lain yang terkandung dalam teh dengan nilai Rs yang diperoleh lebih dari 1,5. Kromatogram larutan standar kafein, larutan sampel teh hijau, serta larutan sampel teh hijau yang diadisi oleh standar kafein ditunjukkan pada Gambar 2 - 4.

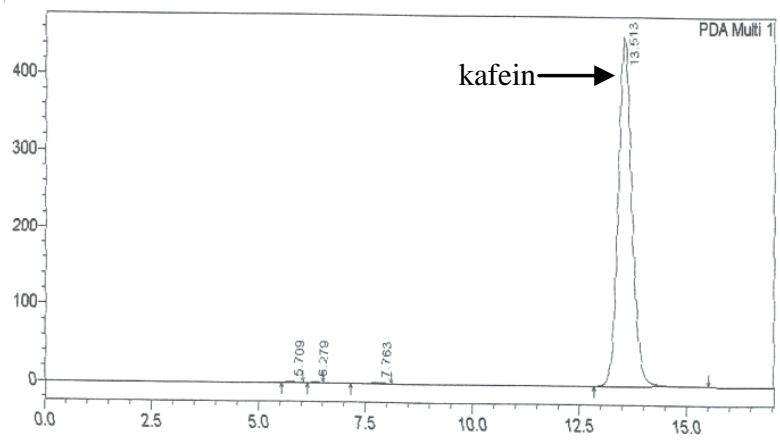

Gambar 2. Kromatogram larutan standar kafein menunjukkan waktu retensi (Rt) 13,513 menit

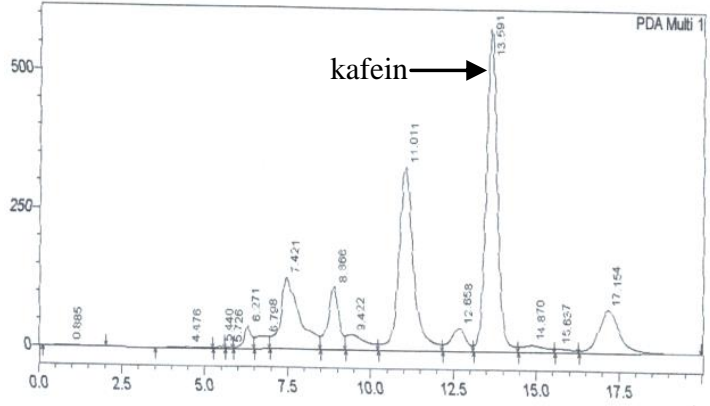

Gambar 3. Kromatogram sampel teh hijau yang mengandung kafein. Puncak kafein muncul pada menit ke 13,491 .

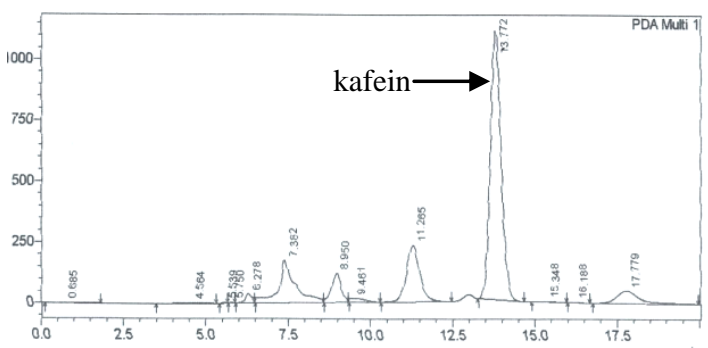

Gambar 4. Kromatogram sampel teh hijau yang telah diadisi dengan larutan standar kafein. Puncak kafein muncul pada menit ke 13,772

\section{Linieritas}

Dari hasil uji linieritas diperoleh persamaan regresi $\mathrm{y}=130981,09 \mathrm{x}-674937,04$ dengan nilai koefisien korelasi $(r)=0,9994(n=5)$ dan nilai $V x o=2,48 \%$. Hal ini menunjukkan adanya hubungan linier antara konsentrasi larutan standar kafein dengan area yang diperoleh karena berdasarkan literatur persyaratan nilai koefisien korelasi (r) $=0,999$ dan nilai $\mathrm{Vxo} \leq 5 \%$ (Yuwono \& Indrayanto, 2005). Kurva baku persamaan regresi dapat dilihat pada Gambar 5.

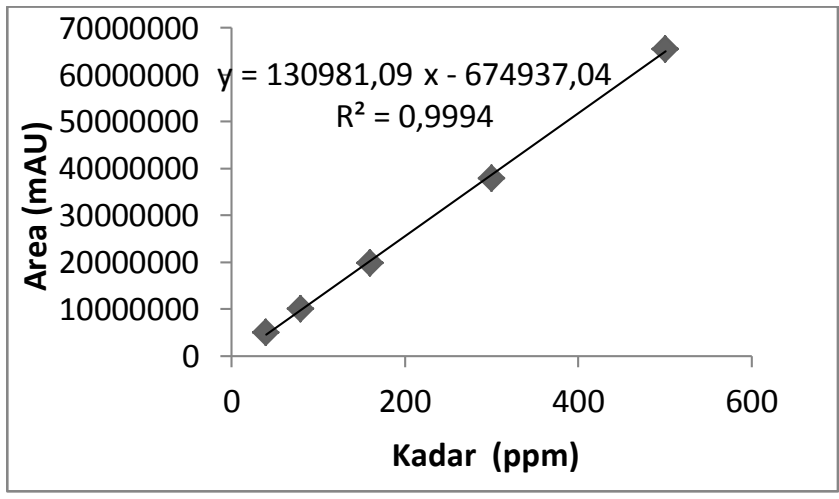

Gambar 5. Persamaan regresi larutan standard kafein 


\section{Akurasi}

Dari hasil perhitungan uji akurasi (Tabel 2) diperoleh persen perolehan kembali sebesar $104,48 \pm 1,94 \%$ dengan $\mathrm{KV}$ sebesar $1,86 \%$. Nilai persen perolehan kembali dan $\mathrm{KV}$ yang diperoleh telah memenuhi persyaratan yaitu persen perolehan kembali sebesar $80-120 \%$ dan KV $\leq 2 \%$ (Yuwono \& Indrayanto, 2005).

Tabel 2. Persen Perolehan Kembali Kafein

\begin{tabular}{|c|c|c|c|c|}
\hline \multicolumn{2}{|c|}{$\begin{array}{l}\text { Kons. } \\
(\%)\end{array}$} & $\begin{array}{c}\text { Kadar } \\
\text { diberikan } \\
(\mathrm{ppm})\end{array}$ & $\begin{array}{c}\text { Kadar } \\
\text { diperoleh } \\
(\mathrm{ppm})\end{array}$ & $\begin{array}{c}\text { Persen perolehan } \\
\text { kembali } \\
(\%)\end{array}$ \\
\hline \multirow{3}{*}{80} & 1 & \multirow{3}{*}{153,19} & 162,36 & 105,98 \\
\hline & 2 & & 163,81 & 106,93 \\
\hline & 3 & & 163,67 & 106,84 \\
\hline \multirow{3}{*}{100} & 1 & \multirow{3}{*}{191,75} & 195,86 & 102,14 \\
\hline & 2 & & 199,17 & 103,87 \\
\hline & 3 & & 199,23 & 103,90 \\
\hline \multirow{3}{*}{120} & 1 & \multirow{3}{*}{215,85} & 218,65 & 101,30 \\
\hline & 2 & & 226,05 & 104,73 \\
\hline & 3 & & 225,83 & 104,62 \\
\hline \multicolumn{4}{|c|}{ Rata-rata \pm SD } & $104,48 \% \pm 1,94$ \\
\hline \multicolumn{4}{|c|}{$\% \mathrm{KV}$} & $1,86 \%$ \\
\hline
\end{tabular}

\section{Presisi}

Presisi dihitung berdasarkan area kromatogram hasil penyuntikan larutan standar kafein. Dari data yang diperoleh didapatkan nilai $\mathrm{KV}$ sebesar $0,35 \%$. Nilai tersebut memenuhi persyaratan nilai KV $<2 \%$ untuk sampel dengan $n \geq 6$ (Yuwono \& Indrayanto, 2005), sehingga dapat dikatakan presisi intraday memenuhi parameter validasi.

\section{Limit deteksi (LOD) dan kuantitasi (LOQ)}

Limit deteksi dihitung dengan menggunakan rumus 3 x standar deviasi (SD)/slope, sedangkan limit kuantitasi adalah 3,3 x LOD. Dari hasil perhitungan (Tabel 3) didapatkan nilai LOD sebesar 0,24 ppm dan LOQ sebesar $0,73 \mathrm{ppm}$.
Tabel 3. Data linieritas untuk perhitungan limit deteksi (LOD) dan limit kuantifikasi (LOQ)

\begin{tabular}{cc}
\hline $\mathbf{x}$ (ppm) & $\mathbf{y}(\mathbf{m A U})$ \\
\hline 1,012 & 135341 \\
\hline 3,036 & 349109 \\
\hline 4,048 & 474439 \\
\hline 5,06 & 595899 \\
\hline 6,072 & 698153 \\
\hline $\mathrm{SD}$ & 8288,43 \\
\hline $\mathrm{y}=112679 \mathrm{x}+17270$ \\
\hline \multicolumn{2}{c}{$\mathrm{r}=0,9989$} \\
\hline LOD $(\mathrm{ppm})$ & $0,24 \mathrm{ppm}$ \\
\hline LOQ $(\mathrm{ppm})$ & $0,73 \mathrm{ppm}$ \\
\hline
\end{tabular}

\section{Penetapan kadar kafein dalam sampel} Pengaruh suhu penyeduhan terhadap kadar kafein

Hasil pengujian pengaruh suhu dan penyeduhan berulang terhadap kadar kafein ditampilkan pada Gambar 6 dan Tabel 4. Berdasarkan data pada Tabel 4, dapat dibuktikan bahwa peningkatan suhu penyeduhan sebanding dengan jumlah kafein yang terlarut dalam sampel sedangkan semakin meningkatnya frekuensi penyeduhan kadar kafein terlarut semakin kecil.

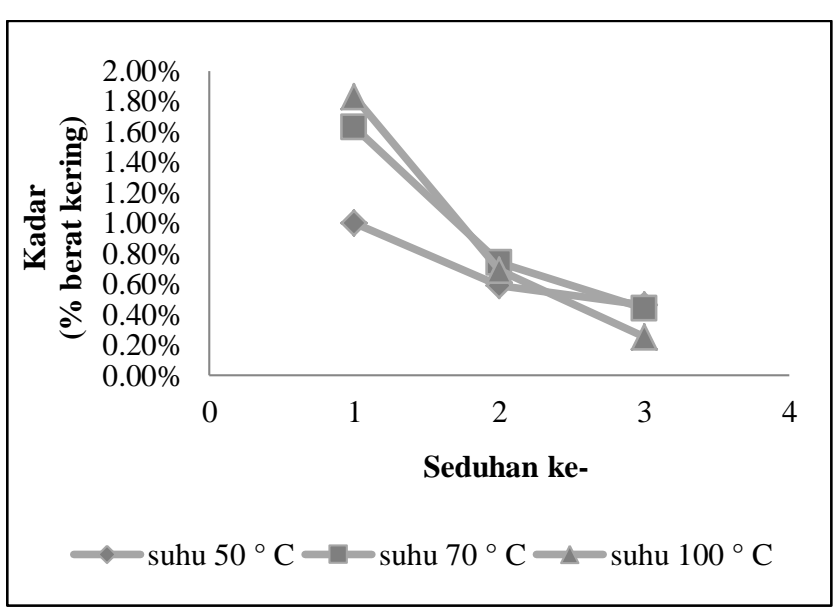

Gambar 6. Hasil pengujian pengaruh suhu dan penyeduhan berulang terhadap kadar kafein 
Tabel 4. Hasil pengujian pengaruh suhu dan penyeduhan berulang terhadap kadar kafein

\begin{tabular}{|c|c|c|}
\hline Suhu & Seduhan ke- & $\begin{array}{l}\text { Kadar kafein } \\
\text { terlarut }(\% \mathrm{~b} / \mathrm{b})\end{array}$ \\
\hline \multirow{3}{*}{$50^{\circ} \mathrm{C}$} & 1 & 1,00 \\
\hline & 2 & 0,59 \\
\hline & 3 & 0,46 \\
\hline \multirow{3}{*}{$70^{\circ} \mathrm{C}$} & 1 & 1,63 \\
\hline & 2 & 0,74 \\
\hline & 3 & 0,44 \\
\hline \multirow{3}{*}{$100^{\circ} \mathrm{C}$} & 1 & 1,83 \\
\hline & 2 & 0,69 \\
\hline & 3 & 0,25 \\
\hline
\end{tabular}

\section{KESIMPULAN}

Berdasarkan hasil analisis menggunakan metode KCKT terpilih, dapat dilihat bahwa kadar kafein di dalam teh hijau dipengaruhi oleh kondisi penyeduhan, yaitu suhu dan jumlah penyeduhan.

\section{DAFTAR PUSTAKA}

Badan Standarisasi Nasional. (2016). Standar Nasional Indonesia 3945. Jakarta: Badan Standar Nasional.

Burnham, T. A. (2001). Drug Fact and Comparison. St Louis: A Wolters Kluwers Company.

Fernandez-Caceres, P. M. J., Martin, M. P. \& Gonzalez, A. G. (2001). Differentiation of Tea
(Camellia inensis) Varieties and Their Geographical Origin According to Their Metal Content. Journal of Agricultural and Food Chemistry; 49; 4775- 4779.

Fulder, S. (2004). Khasiat Teh Hijau Terjemahan. Jakarta: PT. Prestasi Pustakarya.

Hoeger, W. W. K., Turner, L. W. \& Hafen, B. Q. (2002). Wellness: Guidelines for a Healthy Lifestyle (3rd Ed). Belmont: Wadsworth Group.

Misra, H. D., Mehta, B. K., Mehta, M. \& Soni, D. C. J. (2008). Study of Extraction and HPTLC - UV Method for Estimation of Caffeine in Marketed Tea (Camellia Sinensis) Granules. International Journal of Green Pharmacy; 3; 47-51.

Putri, D. D. \& Ulfin, I. (2015). Pengaruh Suhu dan Waktu Ekstraksi terhadap Kadar Kafein dalam Teh Hitam. Jurnal Sains dan Seni ITS; 4; 2337 3520.

Syah, A. N. A. (2006). Taklukkan Penyakit dengan Teh Hijau. Jakarta: Agromedia Pustaka.

Yuwono, M. \& Indrayanto G. (2005). Validation of Chromatographic Methods of Analysis. Profile of Drug Substances, Excipients, and Related Methodology; 32; 243-259. 